\title{
Review Paper: Association between Social Network and Obesity among Adult Population
}

\author{
Xiao Yi Brenda Lee*, Nur Wafiah Yusof, Naganathan Kathiresan Pillai, Christina Gertrude Yap, \\ Nowrozy Kamar Jahan
}

Jeffrey Cheah School of Medicine and Health Sciences, Monash University Malaysia, Kuala Lumpur, Malaysia

Email: ^leexiaoyibrenda@gmail.com, afia_dina@yahoo.com,naganathan.pillai@monash.edu, christina.yap@monash.edu, nowrozy.jahan@monash.edu

How to cite this paper: Lee, X.Y.B., Yusof, N.W., Pillai, N.K., Yap, C.G. and Jahan, N.K. (2022) Review Paper: Association between Social Network and Obesity among Adult Population. Open Journal of Endocrine and $\mathrm{Me}$ tabolic Diseases, 12, 20-46.

https://doi.org/10.4236/ojemd.2022.122003

Received: December 21, 2021

Accepted: February 12, 2022

Published: February 15, 2022

Copyright (อ 2022 by author(s) and Scientific Research Publishing Inc. This work is licensed under the Creative Commons Attribution International License (CC BY 4.0).

http://creativecommons.org/licenses/by/4.0/

\section{(c) (i) Open Access}

\begin{abstract}
Objectives: Our main objective is to establish an association between obesity and social networks among the adult population as well as understanding the underlying mechanisms. We aim to provide suggestions for the development of future interventions to treat obesity. Methods: We carried out a literature search from 4 databases: PubMed, Embase, Scopus and Web of Science. We conducted a systematic search targeting on 3 main concept terms-"social network", "obesity" and "adult". A final pool of 11 articles best fitted for our topic was included. Results: We have established a clear association between obesity and social networks. Single women with the co-living arrangement have a higher waist circumference (WC), consistent with a higher predisposition to obesity seen among single individuals but lone living divorced men had lower WC compared to those with partners. Women with high incomes are less likely to be obese in comparison to highly social men with low income. The degree of the effect on social networks and obesity was inconclusive due to differences in the study population. Generally, women with low social participation tend to be obese. However, non-partnered women consistently showed a higher WC in comparison to their partnered counterparts regardless of participation rates except for divorced women. Living in a neighborhood with access to active transportation, high socioeconomic status, increased levels of social trust and social support reduces the prevalence of obesity. Mechanisms of cultural ideals, nature of employment, stress, gender, self-selection, network influence, social contagion and shared built environment may have contributed to the variation in results obtained. Conclusion: Association between social network and obesity exists. However, its overall effect on body weight is affected by a variety of factors. Sociodemographic factors and network characteristics of the population may influence the impacts on body weight. Therefore, a good understanding of the mechanisms associated will assist the development of effective network-based interventions.
\end{abstract}




\section{Keywords}

Social Network, Obesity, Adults

\section{Introduction}

Obesity is a growing public health crisis [1] [2] [3] [4] [5]. In the past, obesity was regarded only as a problem in high-income countries, but in recent years, its distribution has expanded to many regions regardless of their wealth [1] [6] [7].

Obesity is defined as a chronic disease resulting from the pathological buildup of fat which could potentially be detrimental to health [8] [9]. An individual may belong to any one of the 4 categories: underweight, normal, overweight and obese, based on their calculated Body Mass Index (BMI) in accordance with the World Health Organization classification [10] [11]. BMI ranging from 25 - 29.9 $\mathrm{kg} / \mathrm{m}^{2}$ would be overweight whereas obese individuals would have a BMI greater than $30 \mathrm{~kg} / \mathrm{m}^{2}$ [3] [4] [10] [11]. Variation in threshold limits among different ethnic groups exists where the population with a high risk of developing diabetes and its complications tend to set lower cut-off values [11] [12]. Although BMI has been the common method used to stratify individuals into distinct weight groups, percentage of body fat estimated using the Deurenberg equation was preferred by some authorities on the basis that it provides a relatively accurate degree of fat composition independent of one's muscle mass, therefore, allowing identification of people with a high-fat percentage but seemingly normal BMI [11]. For this, obesity is diagnosed if the fat percentage is more than $25 \%$ in males and more than $33 \%$ in females [11].

In 2016, there were 1.9 billion adults who were overweight, out of these, more than 650 million adults were obese [8]. From 1975 to 2016, the prevalence of obesity had increased by 3 folds worldwide [8]. In terms of gender, females were more likely to be overweight and obese at $40 \%$ and $15 \%$ respectively [8]. Based on the statistics available from 2017, globally, obesity accounted for approximately 4.7 million premature deaths annually which are comparatively much higher than death resulting from road traffic accidents and HIV/AIDS [1]. These alarming figures could be contributed by the predisposition of obese individuals to comorbidities, further increasing their risk of morbidity and mortality [5] [8]. Common complications of obesity are cardiovascular diseases, stroke, diabetes mellitus and several malignancies [1] [3] [5] [13] [14]. The actual mechanisms associated with its comorbidities are currently not clear, however, significant weight reduction was effective in reducing the comorbidities of obesity, suggesting that obesity is highly associated with a variety of metabolic disorder [11]. Apart from that, obese individuals also tend to experience a lower quality of life due to the inability to perform daily activities [3] [15] [16] and being the subject of stigmatization [9] [15].

In Malaysia, the 4 yearly National Health and Morbidity Survey published in 
2019 showed a slight rise in the prevalence of overweight and obesity in adults by $0.4 \%$ and $2.0 \%$ respectively within a 4 year period [10]. The annual death rate for individuals with obesity nearly doubled over a period of 27 years from $6.65 \%$ in 1990 to $11.06 \%$ in 2017 [1]. Similarly, in the United States, 1 in 5 deaths occurred due to obesity and overweight from 1986 to 2006. Additionally, those who were severely obese experience a reduction in life expectancy of up to 20 years in men and around 5 years in women [11]. Malaysia, being the country with the highest rates of obesity in Southeast Asia, poses an economic burden to the country [6]. Nearly $\$ 1.7$ billion were spent solely on medical cost for obesity and overweight-related issues [6]. Similarly, the cost of managing obesity in the United States utilizes $20.6 \%$ of the country's health budget and an additional $\$ 73.1$ billion and $\$ 121$ billion were used on anti-obesity products and services [2].

At present, most weight-based interventions focus mainly on incorporating healthy behaviours such as engagement in physical activity, adherence to a healthy diet regimen and controlling meal portions [2]. Although improvement in weight was seen, the effects were not sustained [9] [11] [17] [18] with significantly large numbers of participants returning to their pre-treatment weight within 5 years [11] [17]. The latter could be due to the increasing availability of large meal sizes, booming fast-food industry and a relatively sedentary lifestyle [17]. Therefore, it is important to identify limitations of conventional treatments of obesity and develop effective and sustainable interventions which are able to address the biological, psychological and social components of daily lives [9] to overcome body weight crisis.

Social network is a complex structure consisting of individuals connected to each other by relationships. In the last decade, studies mainly focus on how these networks contribute to the development of overweight and obesity [19]. It is said that an individual's physical and behavioral characteristics are predominantly shaped by the group of people they frequently associate with [20]. These social relationships can be both beneficial and harmful to a person's behavior [2] [21]. Positive changes have been noted with higher levels of physical activity among teenage girls when they have more physically active friends [2]. Furthermore, it was found that weight-loss interventions produced better results when conducted in groups [19]. On the other hand, having obese social contacts can alter one's attitude towards obesity and their lifestyle choices (e.g., social habits, diet and physical activity) [22]. Furthermore, it was observed that relocation of people originating from poorer countries to richer countries tend to experience lesser weight gain and are at lower risk of getting diabetes as compared to those who remained in their home country [11]. With the limited data available from Africa, high BMIs were seen among Africans who immigrated to Northwestern regions of the world [1]. Thus, future approaches to the management of obesity should note the influence of complex social connections among individuals as potential contributory factors to the development of obesity [20]. 
Despite extensive efforts to combat the troubling rates of obesity, commonly prescribed treatment consisting of lifestyle advices does not seem to produce promising results [23]. This is in line with findings from the study conducted by Finucane et al. revealing a worrying upward trend in BMI worldwide since 1980 [5] [11]. Increasingly, recognition of the role of social network in the understanding of obesity has been accepted, however, there are still limited resources available focusing on how these webs of connections contribute to the development of overweight and obesity [19]. A large majority of research done were to determine the risk of developing overweight or obesity based on the characteristics of specific network groups (such as the friendship group), which highlighted the point that it is possible for clustering of obesity in social groups to occur [19]. However, the use of the social network as interventions for the management of obesity is still unvisited [2]. The aim of this paper is to establish an association between obesity and social network among the adult population and identify the underlying mechanisms. This is vital for the development of holistic interventions to overcome the upsurge in rates of obesity both globally and locally. With this piece of information, we can rely on influential individuals to convey health information and share positive health-related behaviors to the population [2] [12] [19]. A similar strategy has been successful in reducing the spread of HIV/AIDS with the help of social media such as Facebook [24]. Therefore, offline social networks could potentially produce similar results if all aspects of an individual's daily life are taken into account when designing a future intervention for the treatment of obesity.

\section{Methods}

\subsection{Search Strategy and Key Terms}

An electronic literature search was done in March 2021 using 4 databases namely PubMed, Embase, Scopus and Web of Science. Appropriate entry terms and subject headings were identified and entered into each database as part of the search strategy. 3 main concept terms were used across all databases to address the purpose of this review: "social network", "obesity" and "adult". Database specific synonyms and subject headings are provided in the Appendix section of this paper. Several synonyms suggested by the databases were removed as it was either irrelevant or were in foreign languages. These includes "social network analytics", "adipositas", "fat overload syndrome", "obesitas" and "prime adult".

\subsection{Study Selection Criteria}

1) Inclusion criteria: Included articles were those that provided insights to the relationship between social networks and obesity as well as its underlying mechanisms. Papers that provided recommendation for development of future intervention were also accepted. Besides, the study population must fall within the age group of 18 to 65 years old and belong to the overweight category to be included in this review. Only original papers were used. 
2) Exclusion criteria: Papers focusing on pathophysiology of obesity and other related comorbidities were excluded. Studies that examined influence of online social network on weight status as well as effectiveness of online network-

based interventions in the management of obesity were removed.

3) Exception: There were 2 papers in this review that did not meet the age group stipulated in the inclusion criteria but was ultimately included in the study because it contains crucial information pertaining to social network and obesity. Paper written by Hosseini provided information vital for better understanding of the association between social network and obesity. This particular study was the only article that assessed multiple social ties individually and noted the interaction between these relationships contributing to obesity. On the other hand, study conducted by Datar included both adults and children, however, the results were separated according the study subjects.

\subsection{Screening of Articles}

Additional limits for language (English) and publication years (last 5 years) were applied to narrow the search. A total of 477 articles were obtained. 227 duplicate papers were identified and removed. Following this, the remaining 250 papers were divided between the 2 reviewers (L.X.Y.B and N.W.Y) of which L.X.Y.B was allocated to PubMed and Embase whereas Scopus and Web of Science were given to N.W.Y. These papers were then independently screened by title and abstract to ensure it met the eligibility criteria. After completion of this rigorous screening process, there were only 58 articles which met our inclusion criteria. 192 papers were excluded due to the following reasons: use of online social network intervention (62 papers), age of study population not between 18-65 (43 papers), focus of study was on another medical condition and not obesity (35 papers), ongoing research (1 paper), non-stratified results (6 papers) and no relationship between social network and obesity (45 papers). Full text papers were obtained if they met all inclusion criteria or when eligibility of the articles was uncertain based on their title and abstract. During this time, 47 papers were excluded because of the following reasons: use of social media interventions (4 papers), study population not within the stipulated age range (14 papers), ongoing research (1 paper), no link between social network and obesity (21 papers), non-stratified results ( 1 paper) and no full text (6 paper). Only 11 papers best suited the objectives of our review topic on social network and obesity were included for this review. The screening process is summarized in Figure 1.

\section{Results}

Eleven papers were included in this review where 5 papers were allocated to L.X.Y.B and 6 papers to N.W.Y. Information were extracted from the 11 papers and broadly classified into socio-demographic factors and social network characteristics. Besides that, the relationship between the two main concepts is explained based on mechanisms involved. Recommendation for future intervention was also included. 


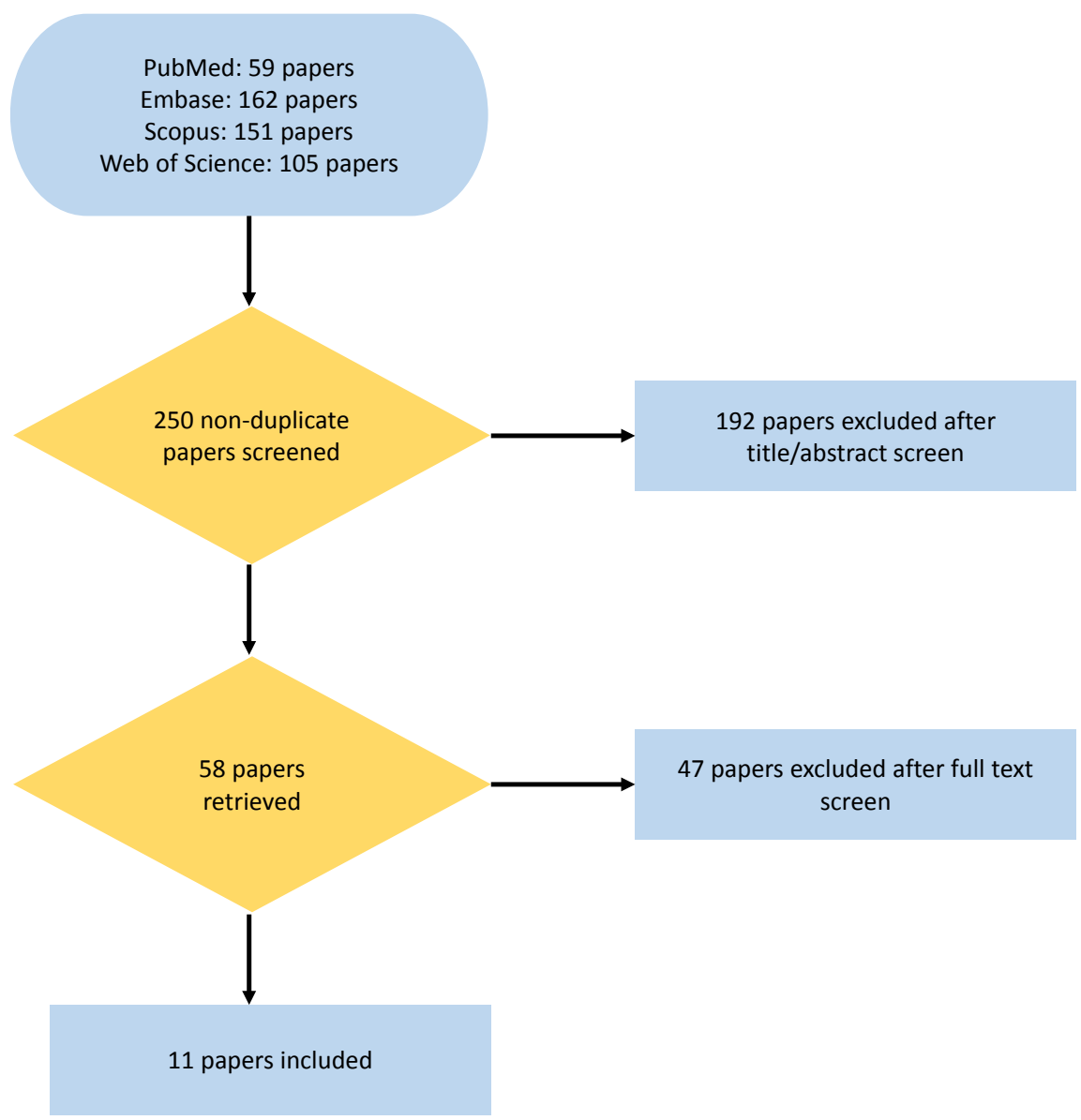

Figure 1. Flowchart for the screening process.

\subsection{Sociodemographic Factors}

1) Marital status: Only single status among men were linked to highest rates of central obesity (OR: 1.18, $\mathrm{p}<0.05$ ) whereas single women were at increased risk of both general (OR: 1.63, p < 0.001) and abdominal obesity (OR: 1.53, p < 0.001 ) as compared to those who were married [25]. In particular, single women experience an increase in WC by $4.32 \mathrm{~cm}$ as compared to partnered women [25].

2) Income: Among males, the independent association between income and BMI was insignificant [26] [27] [28]. However, it was found that correlation between family income to poverty ratio (PIR) and weight is dependent on the degree of social integration [26]. For men in the low-income group, those who are highly socially integrated place them at higher risk of becoming obese $(\mathrm{p}<0.01)$ [26]. As for women, income is negatively associated with BMI. An increase in 1 unit of PIR resulted in a significant drop in BMI by $0.29(\mathrm{p}<0.05)$ [26].

3) Living arrangement: Men who lived alone had lower risk of obesity (OR: $0.85, \mathrm{p}<0.01)$ however, living arrangement did not show any association with weight status among women [25]. Non-partnered women who have co-living arrangement have higher WC than co-living partnered women [25]. However, widowed women living alone had a decrease in WC by $0.97 \mathrm{~cm}(95 \% \mathrm{Cl}:-3.85$ to 1.91) as compared to lone-living partnered women [25]. For men, larger WC 
were associated with lone-living men as compared to co-living men in all marital status except divorced [25].

\subsection{Social Network Characteristics}

\section{1) Social network size}

As for the size of social networks, study by Kim demonstrated that there was a selective negative network effect of social network size on central obesity in both men and women in the community-based group [29]. Both men and women in the community-based group were 1.19 times and 1.29 times more likely to develop central obesity when they had small size of social network respectively (men: $\mathrm{OR}=1.19,95 \%$ CI: 1.01 to 1.39 ; women: $\mathrm{OR}=1.29,95 \%$ CI: 1.15 to 1.45 ) [29]. This demonstrates a negative association between size of social network and central obesity across gender in community-based group [29]. On the other hand, in the hospital-based group, no significant association was observed between size of social network and central obesity in men and only borderline significance for the association was observed among women (men: $\mathrm{OR}=0.99,95 \%$ CI: 0.91 to 1.07; women: $\mathrm{OR}=1.07,95 \%$ CI 0.96 to 1.19 ) [29]. Thus, size of social network exerted a null network effect on central obesity in hospital-based group.

Although it was noted in the study conducted by Wieland that there was a smaller mean size of social network observed in overweight and obese participants, both studies conducted by Wieland and Florez indicated absence of association between size of social network and obesity [30] [31]. Thus, null network effect was noted for size of social network on obesity in the above studies. However, a study conducted by Hosseini observed that smaller network size is protective against abdominal obesity (OR: 0.76, p < 0.001) and general obesity (OR: 0.69, p $<0.01)$ compared to those with larger network size for men. The same association was seen among women $(\mathrm{p}<0.05)$ [25].

WC was positively associated with social network size across all marital status except among women who are divorced [25]. Regardless of the extent of social network, women who are single and widowed recorded higher WC than partnered women [25]. This association is stronger in larger network groups [25]. These effects were less evident among men [25]. Higher WC was recorded in single men with a network consisting of at least 250 contacts than in divorced men with similar network sizes [25].

Positive association was observed between social network size and WC when men participated in 3 or more activities [25]. In low levels or absence of social activities, WC were negatively associated with social network size however, positive association is seen when women participated in 5 or more activities [25].

\section{2) Social participation}

Less than 2 social activities predispose women to abdominal obesity (OR: 1.53) and general obesity (OR: 1.69) [25]. Women who have no social participation experience an increase in WC by $4.19 \mathrm{~cm}$ as compared to those with high social par- 
ticipation [25].

On average, non-partnered women involved in 2 or less social activities had larger WC than their partnered counterparts with less participation [25]. However, an exception was seen in the case of divorced women with the highest level of social participation where the mean WC were greatly reduced [25]. Single and widowed women who joined 8 social activities recorded higher WC than partnered women [25]. Similar results were seen among men but the association was weak [25].

Both men and women have inverse association between social participation and WC for co-living and lone-living [25].

\section{3) Social environment}

Social environment can be defined as "immediate physical surroundings, social relationships, and cultural milieus within which defined groups of people function and interact". It encompasses neighborhood socioeconomic status (SES), perceived crime and physical neighborhood factors such as presence of recreational facilities, features of an active transportation environment and neighborhood aesthetics [32]. Hoenink observed $0.75 \mathrm{~kg} / \mathrm{m}^{2}$ reduction in BMI and $27 \%$ reduced odds of being overweight in neighborhood with high SES level [33]. Besides, the odds of becoming overweight was $9 \%$ lower $(\mathrm{OR}=0.91,95 \% \mathrm{CI}=0.83$; $0.99)$ and $0.21 \mathrm{~kg} / \mathrm{m}^{2}(95 \% \mathrm{CI}=-0.40 ;-0.02)$ reduction in BMI was also noted when there were features of active transportation environment in the neighborhood [33]. Thus, a positive network effect of neighborhood SES and features of active transportation environment with BMI and overweight status was established. However, neither perceived crime nor other physical neighborhood factors such as neighborhood aesthetics and presence of recreational facilities were associated with BMI and overweight status [33]. Thus, no network effect of perceived crime and other physical neighborhood factors on BMI and overweight status was proven.

\section{4) Social trust}

Association of social trust with BMI and overweight status was also tested in the study conducted by Hoenink [33]. $1.28 \mathrm{~kg} / \mathrm{m}^{2}$ reduction was noted when there was a high level of social trust in neighborhood while $1.31 \mathrm{~kg} / \mathrm{m}^{2}$ reduction in BMI was achieved when highest levels of social trust was attained within the neighborhood. This showed a positive association between high level of social trust and reduction in BMI. However, no significant relationship was established between social trust and overweight status [33]. Thus, a positive network effect of high social trust was seen with BMI but not overweight status.

\section{5) Social support}

Among the Lesbian Gay Bisexual (LGB) community, generally, male and female had a lower likelihood of becoming overweight [OR (95\% Cl: female 0.97 (0.93 - 1.00); male $0.95(0.92-0.99)$ ] or obese [female 0.94 (0.88 - 1.00); male 0.92 (0.93 - 1.00)] with higher LGB climate scores [34]. For female LGB, probability of overweight/obesity were lower with increasing LGB climate scores but these re- 
sults were insignificant after adjusting at the college level probably the influence of an inadequate sample size [34]. Among heterosexual and gay males, the risk of overweight and obesity is lower with better LGB climate scores [34]. As a result, this may suggest that an encouraging and helpful support system at college would be beneficial to the health of heterosexual students [34].

However, social support among Hispanic adults did not contribute to the association between social network and obesity, resulting in a null network effect to be observed between social support and obesity [31].

\subsection{Possible Mechanisms for the Association between Social Network and Obesity}

\section{1) Cultural ideals}

Also referred to as "fat bias" where higher body weight could possibly be beneficial for men while lower body weight status would be preferred among women [16]. With that, "fat" men gained higher incomes than thin men whereas "thin" women are given higher wages as compared to "fat" women [16].

The collectivistic culture that is found within Asian American as compared to individualistic culture that was found in European American hindered members within the community to look for social support. This is because individuals aim to reduce relationship-related strain by minimizing burden on other members of social networks. Consequently, people resorted to instrumental support such as social network quantity as compared to emotional support which signified social network quality when they were coping against stress. Thus, this theory was able to explain the positive association of borderline significance seen between size of social network and central obesity across gender in community-based group and women in hospital-based group respectively [29].

\section{2) Nature of employment}

It was found that men in lower socioeconomic groups tend to get jobs which involve physical labour and vice versa which could have possibly justified the weight gain or loss that occurred [26].

\section{3) Stress}

Stress may account for the differences in weight status among men and women [35] which includes gender-based reaction to stress, resulting tension from being treated unfairly and variation in biological responses to stress [26]. Women were more likely to inculcate the "tend-and-befriend" mechanism as a coping strategy against stress. They became more dependent on their social network as compared to men to avoid stressors and threat. This mechanism has then allowed women to harvest social support from their social network as part of their coping strategy [29].

\section{4) Social isolation}

Among African Americans, social isolation has been found to reduce sedentary life practices among men and women. For women, it is the result of increased rates of physical activity from lesser contact with their inactive friends while men were more inclined to inculcate healthier diet into daily living as compared to so- 
cially active men who eat out and drink frequently, causing them to have lower BMI [30].

\section{5) Network influence}

Presence of social cohesion in a modern residential area allowed exchange of opinions between members regarding health behaviors constituting a pleasing social environment. This in turn led to a positive effect on health behaviors causing decrease in BMI and overweight status in participants [33].

Individuals' BMI were negatively associated with perceived overweight/obesity within their social network groups. $1 \%$ increase in exposure to overweight/obesity led to a decrease in public housing residents' BMI by $0.05 \mathrm{~kg} / \mathrm{m}^{2}(95 \% \mathrm{Cl}:-0.10$ to $0.00, \mathrm{p}=0.06$ ) [36]. Among individuals who perceived they had greater exposure to overweight/obesity experience a reduction in BMI by $4.22 \mathrm{~kg} / \mathrm{m}^{2}(95 \%$ $\mathrm{Cl}:-6.98$ to $-1.46, \mathrm{p}<0.01)$ and are at lower probability of overweight/obesity (RR: $0.75,95 \% \mathrm{Cl} 0.61$ to $0.93, \mathrm{p}=0.01$ ) than those who had lesser exposure [36].

Weight loss intentions in a particular social group were found to influence others to follow the same behavior. Likelihood of having high weight loss intentions was 4 times higher if majority of social contacts were trying to lose weight than those with fewer contacts engaging in weight loss.

\section{6) Self-selection}

The proposed mechanism that mediates the association seen in women and those who are younger than 30 years old is self-selection. For younger participants, due to higher acceptance towards obesity, this has resulted in them having a higher number of social networks that were obese or overweight. A blunted effect, on the other hand, contributed to the disparity seen between men and women. The blunted effect was selectively identified in men due to the gap in self-perceived overweight or obese as well as lack of overweight and obese perception towards their social network [31].

\section{7) Social contagion}

Families of military personnel assigned to installations with high County Obesity Rates (COR) were found to have higher BMI and increased risk of overweight and/or obesity than those allocated to counties with lower COR [37]. Greater strength of correlation between COR and body weight of military families were observed with increasing exposure to the county represented by longer duration of time spent at installation and off-installation residences [37]. A $1 \%$ rise in county obesity rates is linked to an increase in BMI by 0.08 in parents included in the study cohort $(95 \% \mathrm{Cl}, 0.02-0.13)$ and a $5 \%$ higher risk of developing obesity (OR: 1.05; 95\% Cl: 1.03 - 1.08) [37].

\section{8) Shared built environment}

Presence of a pleasing social environment in a neighborhood could be attributed to positive social influence and social engagement within members of the neighborhood. These factors which were commonly associated with urban neighborhood and high neighborhood SES would exert a profound positive impact on 
health behaviors which in turn influences BMI and overweight status. Perceived crime on the other hand, was not a determinant for BMI and overweight status as individuals did not acknowledge it to be as important as social safety or social trust in body weight. Lastly, the theory also included socio-ecological models which mentioned that tiers of environmental influences led to formation of health behaviors. However, only certain interactions were observed in this study to have a supportive role as suggested by the model which further emphasized the complex relationship between residential environment and health behavior. As an example, when there was easy access for active transportation in the environment, this will help members of neighborhood to recognize it as an opening to lose weight, which in turn, promotes increase in physical activity resulting in weight reduction. However, if the factors are assessed independently from each other such as presence of recreational facilities and neighborhood aesthetics, it resulted in no direct influence on BMI and overweight status [33].

The impact on weight may be similar among individuals who have similar access to resources such as recreational facilities and food [37]. Shared built environment did not explain the positive association between COR and body weight among army families [37]. However, due to inadequacy of subjective (using parent-reported Neighborhood Environment Walkability Scale for Youth scores) objective (using Geographic Information Systems and Robert Wood Johnson County Health Rankings data) tools used to assess the surrounding built environment, they were not able to a definite conclusion as to whether shared built environment contributed to the results aforementioned [37].

\subsection{Suggestions on Future Intervention}

Making use of peer influence for the purpose of modifying health-related behaviors among the adult population may be effective but further research is needed to determine necessary adjustments to behavioral and social targets according to the population group [36]. Additionally, health professionals could also utilize existing social support available to the client who includes family and friends when promoting the need to maintain a healthy weight [26].

With the establishment of association between social network and obesity as well as its underlying mechanisms, studies have suggested interventions incorporating social network in public health initiatives [26]. Besides, appropriate interventions targeting specific mechanisms can be drawn such as introducing gamification designs in physical activities, improving features of active transportation environment and implementing systemic approach to combat obesity [33] [38] [39]. A summary of suggested interventions can be seen in Table 1.

\section{Discussion}

\subsection{Association between Social Network and Obesity}

There is a proven association between social networks and obesity in the adult 
Table 1. Suggested social network interventions for obesity.

\begin{tabular}{ll}
\hline Article name & \multicolumn{1}{c}{ Suggested interventions } \\
\hline Campbell, $2019 \begin{array}{l}\text { - Incorporation of social network in public health initiatives. } \\
\text { available through friends and family when promoting importance } \\
\text { of maintaining a healthy weight. }\end{array}$ \\
- $\begin{array}{l}\text { Application of peer influence in targeting change in health-related } \\
\text { behaviour among adults may be useful however more research is } \\
\text { required to determine how behavioural and social targets may need } \\
\text { to be adjusted based on the population. }\end{array}$ \\
Harisson $2019 \begin{array}{l}\text { - Usage of gamification design as an intervention to increase physical } \\
\text { activity among families in the community. }\end{array}$ \\
$\begin{array}{l}\text { - Improve social network, social cohesion, social trust and SES status } \\
\text { in a neighbourhood by promoting activity friendliness of the } \\
\text { neighbourhood and adding crossings or streetlight in the } \\
\text { neighbourhood to improve features of the active transportation } \\
\text { environment in the neighbourhood. }\end{array}$ \\
$\begin{array}{l}\text { - Since system approach has been proven successful in the fields of } \\
\text { infectious disease prevention and control, adoption of systemic } \\
\text { approach to combat obesity has been identified. This can be } \\
\text { achieved by applying } 5 \text { of the following efforts in the interventions } \\
\text { drafted: promoting more universal approaches, involving } \\
\text { multidisciplinary expertise, applying system methods, } \\
\text { implementing systems orientation to traditional approaches and } \\
\text { finally, connecting research, education, policy and action. }\end{array}$ \\
\hline
\end{tabular}

population. Larger social network size comprising of family and friends among low-income population predispose individuals to obesity [29]. On the other hand, due to the difference in the socio-cultural aspect, having a small network of friends could either lead to low BMI or increased risk of obesity [29] [30]. An article published by Cockerham revealed that those in the working and lower middle class tend to indulge in unhealthy lifestyle habits due to restricted life opportunities and traditional male socialising activities such as binge drinking and heavy alcohol intake [40]. Tomaka is able to demonstrate both positive and negative influences that may arise from having a large size of social network in Caucasian and Hispanics population based on the study conducted [41]. Positive outcomes were observed between social support and improvement in diseases such as diabetes, hypertension, stroke, arthritis, emphysema while negative association was noted between social isolation and development of liver disease. The negative association between social isolation and development of liver diseases is due to cultural factors such as consuming alcohol as part of social customs in the Caucasian and Hispanics population while the positive associations are due to presence of family support and social support in the communities. This further shows that the size of social networks may support or oppose development of obesity in the population depending on the contextual factors in play [41]. 
It was seen that greater exposure to overweight and/or obesity in different geographical location can prove to have positive or negative effects on weight status [36] [37]. A small positive but not significant relationship between obesity and network exposure to obesity is established in a study conducted by Pollack in Montgomery County, Maryland, a higher socioeconomic status public housing area [42]. This indicates that geographical location may reflect socioeconomic status and thus impact the development of overweight and obesity in the community [42].

LGB students who were given more support were found to be at lower odds of obesity and overweight among college-goers [34]. Another pilot study conducted by Marcoux demonstrated any form of social support regardless of size of social network impacts positively on weight control and weight loss which thus proves that social support should be targeted as means to combat overweight and obesity in the population [43].

As for social network characteristics, self-selection had led to the presence of clustering within similar social network of obese and overweight individuals [31]. A cohort study conducted by Pachucki highlights influence and consistency in food choices and food patterns in participants based on existing social ties [44]. This further proves that clustering within similar social network based on food pattern impacts in the development of overweight and obese individuals [44].

At the community level, social neighborhood factors such as social closeness, social trust and neighborhood SES were proven to be mediating factors between BMI and overweight status [31] [33]. It is found by Hystad that there is an increase in health-behavior change when there is presence of community belonging [45]. This reflects that one's health is improved when there is better social cohesion within the community as it promotes indulgence in positive health behaviors such as exercise, diet and weight loss [45]. Finally, Yang were able to highlight that social strain increases risk of overall obesity from young to late adulthood which demonstrated that social participation and support plays important role in preventing obesity in the population [46].

Thus, it can be concluded from the studies that there are some significant factors that mediate the association between social network and obesity in adults. Targeted interventions should be directed to overcome these factors which include single individuals, people with low income as well as socially isolated individuals in a supportive culture or community. On the other hands, interventions should also incorporate or strengthen existing factors that can aid in the prevention of overweight and obesity such as improving socioeconomic status and features of active transportation in a neighborhood.

\subsection{Impact of COVID-19 Pandemic on Obesity}

\section{1) Food insecurity}

The underprivileged people group experiences food insecurity in the midst of 
the pandemic resulting in changes in dietary practices towards unhealthy ones which contributes to development of diet related conditions [47] [48]. Examples includes individuals opting for high calorie food items as they are readily available and affordable for those in the low socioeconomic group due to financial restraints and lack of resources [48] [49].

\section{2) Deteriorating psychosocial health}

The occurrence of the pandemic has resulted in psychological stress due to restrictions on social interactions thereby leading to a rise in individuals experiencing loneliness [48]. The pandemic has had a negative influence on food related behaviors where it promoted food hoarding culture and consumption of energy rich food [48]. This coupled with reduced social interactions causes an increase in obesity rates [48]. Negative feelings associated with home quarantine were found to be alleviated by impulsive eating habits such as emotional eating [48]. Inability to dine out has led to reduction in mindful eating with an increase in incidence of overeating and poor dietary choices [48]. It is difficult to remain active during the pandemic due to closure of gyms and restriction on outdoor activities [48].

\section{3) Social isolation}

An emergency social isolation has been called upon by many governments across the world as a response to curb the spread of COVID-19 in early 2020 [49]. These prolonged forced confinements were observed to have a negative impact on obesity as obesity pandemic worsens throughout populations across the globe [49]. Throughout the globally implemented lockdown, it was noted that the period of indolence and comfort eating has increased exponentially causing nutritional energy balance to tilt towards weight gain [49].

\section{4) Behavioral changes}

On the other hand, rapid increase of screen time was also identified to impact obesity negatively as calorie intake exceeds energy expenditure due to escalation in on-line education, social media usage and work from home [49]. Disruption in work patterns due to home-schooling and work from home implementation also caused behavioral changes which influenced physical activity patterns, thus becoming one of the major impacts of COVID-19 on obesity [49].

\subsection{Mechanism and Impacts of Social Network}

One of the mechanisms affecting the association between social network and obesity is cultural ideals. Our findings suggest that fat males were given higher pay than their female counterpart. It was also shown that a $1 \%$ increase in BMI among women resulted in $0.6 \%$ reduction in family income as compared to men. As a result, these individuals have trouble gaining employment, pushing them into the low-income category [50] [51]. Additionally, it was noted that obese women earned $10 \%-12 \%$ lesser than non-obese individuals. The impact of such practices results in women being unable to break out of vicious cycle of obesity. Therefore, employers should be aware of such occurrence at the workplace and devel- 
op policies against it to ensure well-being of all employees.

Next, collectivistic culture among Asian American has resulted in reduced social support leading to the rise in obesity across gender. Westerners were more likely to seek support from others than Asians when faced with challenges while working towards their goals [52] [53] [54]. This is because Asian culture emphasizes on keeping harmony between social members, therefore unnecessary disclosure of personal issues may burden others and complicate the process of integrating into society [52] [53] [54]. Therefore, it is important to understand the cultural aspect of the target population when developing intervention to counter obesity.

Another potential mechanism is nature of employment. We found that men from low SES tend to have jobs that require physical labour, sparing them from obesity. Similar hypothesis was postulated during a study involving shift workers but it did not reach statistical significance [55]. At present, there has been no published papers addressing both socioeconomic status and nature of employment concurrently to assess its effects on body weight. However, independent association between SES and obesity showed that both low and high-income countries are equally affected by the rising rates of obesity [56]. But, socially disadvantaged groups are thought to have more exposure to factors predisposing individuals to obesity or are more sensitive to their effects [57]. Contrary to popular opinion, physically taxing occupations had more overweight individuals while those who engage in exercise during their free time had low body weight among the rural Swedish population [58]. The Healthy Worker Project also revealed positive correlation between work-related physical activity (WRPA) and obesity in men and women [59]. This study also concluded that job activity is not a predictive factor for weight loss because individuals who experience higher WRPA are from the low SES category which possibly acts as a confounding factor [59].

Variation in reaction to stress from unfair treatment subjected to individuals with non-ideal body weight contributes to the development of obesity. Women utilized the "tend-and-befriend" mechanism and seek help from their social group to cope with stress. Overall, women tend to people-centred, generous and cooperative while men were more self-centred with regards to their own well-being and interest and less likely to risk themselves to help others [60]. It is true that individuals are judged and stigmatized by others because of their physical appearance [61]. Consequently, they would be offered lower pay and given lesser job opportunities leading to job stress which in turn increases their BMI [61]. This is closely related to the change in food preference towards high calories items with high saturated fat and sugar content [62].

Social isolation resulted in lower BMI than those who are socially inclined across genders following an increase in physical activity among women and healthier eating habits among men. This association has been corroborated by studies done in Germany where socially inactive women were less likely to be obese [63]. In contrast, study done in Switzerland and England showed that high degree of 
social exclusion predisposed individuals to physical inactivity [64] [65] [66] and poor diet consisting of lesser daily consumption of fruits and vegetables increasing their obesity risk [64] [66]. Therefore, the effects of social isolation differ according to the population demographics.

Increased exposure to overweight or obesity in a neighborhood promotes reduction in BMI. Although this finding contradicts previous study conducted by Christakis and Fowler and Pollack, it was thought that exposure to unhealthy body weight would motivate individuals to work towards achieving normal body weight [22] [42]. A study conducted among adolescent showed that negative peer influence resulted in the decrease in BMI when prevalence of obesity was high [67]. Adoption of weight loss behaviors was found to be highly dependent on weight loss intentions of their social contacts. Similar findings were seen among participants of a behavioral weight loss program where the decision to join the program was greatly influenced by the participation of their social contact. These individuals were also found to be more participative throughout the program and experience more weight loss than those with no social contact [68].

Several studies have supported our finding that presence of social cohesion among members of an urban neighborhood provides a conducive environment for reduction in BMI and overweight status [69] [70] [71]. There is a 14\% risk reduction in obesity among residential areas with high social trust versus low social trust [71]. Communities with high collective efficacy were found to have individuals who are willing to intervene to create a healthy local environment to benefit the community [69]. Furthermore, they are also more open to express their opinion on behaviors including diet and exercise, therefore these adults lead by example, by serving more nutritious foods, incorporating exercise where possible and reducing screen times among children in hope to encourage others to adopt a healthy lifestyle [69].

People living in areas with high rates of obesity for a longer duration tend to have higher BMI and more likely to be obese and overweight themselves. The data from this study was insufficient to reach a conclusion, however, it suggested that social contagion could have played a role. Being in constant contact with people of a certain body size may influence an individual's choice of food. Study done by McFerran among female undergraduates showed that the weight of an individual is influenced greatly by people in their immediate setting and is also related to how one perceived themselves in comparison to others in the setting [72]. Non-dieters were found to consume more snacks when they were served by a thinner waitress than a heavier one. Additionally, those on a diet tend to be more receptive towards food recommendation given by a heavier waitress than a thinner one [19].

Urban neighborhoods and higher SES were found to reduce the rates of obesity and overweight. This is found to be true as obesogenic environment tend to cluster in less affluent neighborhoods [73]. It was reported that low-income neighborhood areas who are highly deprived have more access to tobacco, alcohol and unhealthy food than those living in wealthier areas [74]. Furthermore, these peo- 
ple are unlikely to own cars, which further prevent them from getting healthy food [75]. Therefore, it is fair to suggest that shared built environment is at play contributing to development of obesity. With this, improving access to healthy food options is vital in vulnerable populations to improve their living standard and health status.

\subsection{Current Management Approach for Obesity}

The mainstay approach towards management of obesity according to the Malaysian Clinical Practice Guideline consists non-pharmacological treatments. A trial of weight loss with a target of $10 \%$ weight reduction over 6 months is recommended to all overweight and obese individuals [76]. Once achieved, weight maintenance must ensue. It is considered successful if weight gain is less than $3 \mathrm{~kg}$ over 2 years and at least $4 \mathrm{~cm}$ of sustained decrease in waist circumference [76]. However, individuals can be advised to prevent further weight gain if weight loss strategy has failed. A minimum duration of follow up of 1 year is recommended as regular contact with the treatment team provides a supportive environment, which is a major determinant of successful weight loss in the long run [76]. Dietary changes including calorie restriction to 500 to $1000 \mathrm{kcal} /$ day to ensure maintenance of weight and preventing weight gain [76]. To ensure compliance, dietary education is vital. 45 to 60 minutes of moderate intensity or lesser amounts of vigorous activity is needed after obtaining medical clearance from the treating doctors based on the patient's health status [76]. These exercise programmes must meet the FITT (frequency, intensity, time and type of exercise) criteria in order for it to be sustainable [76]. Apart from that, behavioral therapy aiding in changing eating habits has been found to be a useful adjunct to maintain weight loss. The best approach would be a multimodal treatment strategy as it has been associated with the highest reduction in weight [76].

Pharmacological treatment which includes the use of orlistat, sibutramine or phentermine can be offered if BMI $>27.5 \mathrm{~kg} / \mathrm{m}^{2}, \mathrm{BMI}>25 \mathrm{~kg} / \mathrm{m}^{2}$ with comorbidities or have symptomatic complications of obesity [76]. Surgery is reserved for individuals with morbid obesity (BMI $>40 \mathrm{~kg} / \mathrm{m}^{2}$ ) with existing comorbidities, failure of other treatments and associated with high risk of morbidity and mortality [76].

Despite all these recommendation in place since year 2004, the prevalence of obesity in Malaysia has been on the rise. Therefore, the underpinning factors preventing success of strategies highlighted in the local guidelines must be identified and analyzed carefully taking into account the dynamics of the community and developing interventions that suits the given population. This is urgently required as the negative impacts of obesity affect both physical and mental health of an individual.

\subsection{Association between Obesity and Depression and Its Underlying Mechanism}

Bidirectional association between obesity and depression has been established. 
Regardless of gender, there is a $55 \%(95 \% \mathrm{Cl} 1.22$ to $1.98, \mathrm{p}<0.001)$ increased risk of developing depression over time among obese individual while depressed individuals were $58 \%(95 \% \mathrm{Cl} 1.33-1.87, \mathrm{p}<0.001)$ more likely to become obese [77].

The biological mechanism underlying these associations includes inflammation and dysregulation of the hypothalamic-pituitary-adrenal axis (HPA). Adipose tissues induce the body to enter a state of low-grade inflammation which promotes secretion of a broad range of pro-inflammatory factors known as adipokines [78]. In rat models of obesity, it was found that hippocampal inflammation resulted in more emotional changes [79]. Additionally, circulating levels of inflammatory markers such as IL-6 and C-reactive protein is directly proportional to the severity of mood symptoms in women suffering from severe obesity [78]. Hyperactivity of the HPA axis resulting in an increase in hormones such as corticotropin-releasing hormone (CRH), adrenocorticotrophic hormone (ACTH) and cortisol found in depressed patients explains its contribution to development of obesity [78] [80].

Psychological and behavioral mechanism for obesity includes negative perceptions about one's body image resulting in difference in treatment especially in a community with high beauty standards, adoption of unhealthy dietary practices due to depressed mood and changes in food choices in times of distress in line with the "comfort food theory" stating that stress increases consumption of appetizing and high fat content food [78] [81].

\subsection{Practical Intervention to Combat Obesity}

\section{1) Altering current food environment to promote healthy diet}

The environment surrounding current food uptake in an individual or community can be altered by increasing access to healthier range of food, restricting advertisements on unhealthy food items as well as marking up prices and giving discounts for unhealthy food and healthy food respectively.

In order to promote easy access to healthy food in the community, public venues such as schools, parks, playgrounds and city buildings are appropriate target as they are common community gathering areas. A study conducted by Wilbur demonstrated an increase in total sales relative to baseline by $59 \%-100 \%$ when lower calorie items were added to vending machines as compared to just serving regular calorie items in a large office setting [82]. On the other hand, Moore demonstrated that distance to nearest supermarkets may be affecting access to healthy food such as fruits and vegetables in the community [83]. As compared to participants who have stores near their house, those with no supermarkets within 1 mile from their neighborhood were $25 \%$ less likely to indulge in healthy diet. It was also identified that areas with worst ranked food availability to contribute to the participants being $25 \%$ - 35\% less likely to have a healthy diet as compared to areas with best ranked food availability [83].

Another effective intervention that can be implemented includes restricting 
advertisements on unhealthy food items. A study by Zimmerman to investigate effects of televised food advertising on adult food choice implicated for adults exposed to food advertising are $28 \%$ more likely to eat unhealthy food as compared to those who are not exposed to food advertising [84]. The same study also highlighted that the total caloric value in the food chosen by adults exposed to food advertising are $65 \mathrm{kcal}$ higher as compare to the control group [84]. These results reflect positive impact may be achieved if unhealthy food advertisement ban is implemented [84]. However, it is vital to note that a comprehensive ban on all ranges of unhealthy food such as fast-food, high calorie food and sugary beverages should be implemented across all types of media while setting ban on cigarette as an example in mind. This is because selective media ban will only lead the food and beverage (F\&B) industry to prey on other non-banned media [85].

In order to shape the current food environment to be healthy, specific intervention such as marking up prices for unhealthy food vs providing incentives such as price discount for healthy food respectively have to be implemented. Multiple studies have demonstrated that price of food influences food intake and consumption especially in those of lower socio-economic status. As a result, they are more likely to consume fatty meats, refined grains and added fats in their daily diet which are cheaper but less nutritious [86]. Thus, this intervention will focus on price elasticity on food products which can be targeted to combat overweight and obesity community with lower socio-economic status. The effect of price elasticity can be applied to specific types of food consumed and quantity of food consumed.

The probability of consuming specific type of food is significantly reduced when there is a hike in price for the food. As an example, Guo demonstrated significant reduction in consumption of rice by 2 times when the price of rice was increased [87]. With the increment in the price of rice, it was also observed that consumers alternated to other available and cheap source of food such as wheat flour and coarse grains, which recorded a rise of 0.77 and 1.63 times in consumption respectively [87]. This finding is also supported by another study conducted by Jeffery [88]. When there was a price reduction of $10 \%, 25 \%$ and $50 \%$ in low-fat items sold on vending machine, there was a corresponding escalation in purchase of the low-fat items by $9 \%, 39 \%$ and $93 \%$ respectively [88]. Guo also proved that price elasticity exerts a small but significant effect of quantity of food consumption [87]. They noted that when the price of rice was increased, the amount of rice consumed decreased by 0.12 times [87]. Applying the concepts of price elasticity across socioeconomic status, it was found that an increase in the price of rice resulted in a significant drop of 0.54 times in terms of rice consumption in the lower socioeconomic status community as compared to only 0.25 times of drop in rice consumption in those with a higher socioeconomic status [87]. It was also shown that the poor are more likely to shift their choice of meal to cheaper and more available options when the price of food is 
increased [87]. This is clearly demonstrated as wheat flour and coarse grains consumptions in those from lower socioeconomic status increase by 0.32 and 0.64 times respectively when the price of rice is increased as compared to only a small increase in consumptions of wheat flour and coarse grains in the richer populations by 0.23 and 0.19 times respectively [87]. This concludes that the price responsive effect is more pervasive in the poor as compared to the rich [87].

\section{2) Promoting physical exercise as part of healthy lifestyle}

Upgrading outdoor recreational facilities, improving infrastructure to support walking and cycling besides enhancing active transportation in a community or neighborhood are means of promoting physical exercise as part of healthy lifestyle.

Sallis concluded that exercise habits in a neighborhood community was significantly affected by density of total exercise's facilities around one's home which can be either free or pay facilities $(\mathrm{F}=4.5)$ [89]. It was also demonstrated in the same study that presence of specific facilities related to specific activities significantly affect the perceived convenience to exercise in the community such as presence of swimming pool for swimming activities $(F=81.7)$ [89] [90]. Study conducted by Brownson was also able to promote access to physical activity in their study as $18.2 \%$ of the trail users attributed availability of the walking trail as a free place to exercise as an aspect of the trail which they prefer the most [89] [91]. Thus, it is proven that upgrading outdoor recreational facilities reduced perceived barriers among community to exercise and hence encourage people in the neighborhood to exercise. On the other hand, increasing and improving infrastructure to support activities like walking and cycling also proves to engage the community into habits of exercise. The same study also demonstrated that presence of walking trails access in rural communities led to significant rise in physical activity among the population [91]. This was proven by the increase in the amount of walking in $55.2 \%$ of avid users [91]. Finally, promoting and enhancing active transportation features in the neighborhood are proven to intervene with overweigh and obesity issue effectively. A significant negative linear trend can be seen between energy expenditure due to physical activity (PEA) with BMI and waist circumference (W) in the study conducted by Wagner [92]. As compared to those who did not walk or cycle to work frequently, a $0.31 \mathrm{~kg} / \mathrm{m}^{2}$ reduction in $\mathrm{BMI}$ as well as $1 \mathrm{~cm}$ lower $\mathrm{W}$ were observed when an individual spent $10 \mathrm{MET}$ hour/week cycling or walking to work which is equivalent of $30 \mathrm{~min}$ per day [92]. In conclusion, improvement in the infrastructure in the neighborhood such as walking and cycling trails will undoubtedly encourage active transportation to places by the community and thus prevent development of overweight and obesity in the community.

\section{Conclusion}

In summary, specific sociodemographic factors and social network characteristics, as well as gender, affect individuals' body weight differently. The establishment 
of the association between social network and obesity and its mechanisms should be utilized in the development of the future intervention.

\section{Acknowledgements}

The authors would like to thank all library and administrative staff who have helped in one way or another during the process of this literature review.

\section{Conflicts of Interest}

The authors declare no conflicts of interest regarding the publication of this paper.

\section{References}

[1] Ritchie, H. and Roser, M. (2017) Obesity. Our World in Data. https://ourworldindata.org/obesity\#citation

[2] Fuentes, N.S., Rogers, A. and Portillo, M.C. (2019) Social Network Influences and the Adoption of Obesity-Related Behaviours in Adults: A Critical Interpretative Synthesis Review. BMC Public Health, 19, Article No. 1178. https://doi.org/10.1186/s12889-019-7467-9

[3] Wang, Y.C., McPherson, K., Marsh, T., Gortmaker, S.L. and Brown, M. (2011) Obesity 2: Health and Economic Burden of the Projected Obesity Trends in the USA and the UK. The Lancet, 378, 815-825. https://doi.org/10.1016/S0140-6736(11)60814-3

[4] Ng, M., Fleming, T., Robinson, M., Thomson, B., Graetz, N., Margono, C., et al. (2014) Global, Regional, and National Prevalence of Overweight and Obesity in Children and Adults during 1980-2013: A Systematic Analysis for the Global Burden of Disease Study 2013. The Lancet, 384, 766-781. https://doi.org/10.1016/S0140-6736(14)60460-8

[5] Finucane, M.M., Stevens, G.A., Cowan, M.J., Danaei, G., Lin, J.K., Paciorek, C.J., et al. (2011) National, Regional, and Global Trends in Body-Mass Index since 1980: Systematic Analysis of Health Examination Surveys and Epidemiological Studies with 960 Country-Years and 9.1 Million Participants. The Lancet, 377, 557-567. https://doi.org/10.1016/S0140-6736(10)62037-5

[6] World Health Organization (2019) Sugary Drinks Tax Important First Step, But Obesity in Malaysia Demands Further Action. World Health Organization, Geneva. https://www.who.int/malaysia/news/commentaries/detail/sugary-Drinks-Tax-Impo rtant-First-Step-But-Obesity-In-Malaysia-Demands-Further-Action\#: :text=The\%2 0economic\%20cost $\% 20$ to\%20Malaysia,to\%20absenteeism\%20or\%20medical\%20lea ve

[7] Seidell, J.C. and Halberstadt, J. (2015) The Global Burden of Obesity and the Challenges of Prevention. Annals of Nutrition and Metabolism, 66, 7-12. https://doi.org/10.1159/000375143

[8] World Health Organization (2020) Obesity and Overweight. https://www.who.int/news-Room/fact-Sheets/detail/obesity-And-Overweight

[9] Jessen-Winge, C., Ilvig, P.M., Thilsing, T., Lee, K., Fritz, H. and Christensen, J.R. (2020) Health Professionals' Perceptions of Weight Loss Programmes and Recommendations for Future Implementation: A Qualitative Study. BMJ Open, 10, Article ID: e039667. https://doi.org/10.1136/bmjopen-2020-039667 
[10] Institute for Public Health (2020) National Health and Morbidity Survey 2019: Vol 1: NCDs-Non-Communicable Diseases: Risk Factors and Other Health Problem. Institute for Public Health, Malaysia.

[11] Hamdy, O. (2021, March 5) Obesity. Medscape. https://emedicine.medscape.com/article/123702-Overview\#a6

[12] Shi, L., Zhang, L. and Lu, Y. (2020) Evaluating Social Network-Based Weight Loss Interventions in Chinese Population: An Agent-Based Simulation. PLoS ONE, 15, Article ID: E0236716. https://doi.org/10.1371/journal.pone.0236716

[13] Flegal, K.M., Graubard, B.I., Williamson, D.F. and Gail, M.H. (2007) Cause-Specific Excess Deaths Associated with Underweight, Overweight, and Obesity. JAMA, 298, 2028-2037. https://doi.org/10.1001/jama.298.17.2028

[14] Templin, T., Hashiguchi, T.C.O., Thomson, B., Dieleman, J. and Bendavid, E. (2019) The Overweight and Obesity Transition from the Wealthy to the Poor in Low- and Middle-Income Countries: A Survey of Household Data from 103 Countries. PLoS Medicine, 16, Article ID: e1002968. https://doi.org/10.1371/journal.pmed.1002968

[15] Forhan, M.A., Law, M.C., Vrkljan, B.H. and Taylor, V.H. (2010) The Experience of Participation in Everyday Occupations for Adults with Obesity. Canadian Journal of Occupational Therapy, 77, 210-218. https://doi.org/10.2182/cjot.2010.77.4.3

[16] Kolotkin, R.L. and Andersen, J.R. (2017) A Systematic Review of Reviews: Exploring the Relationship between Obesity, Weight Loss and Health-Related Quality of Life. Clinical Obesity, 7, 273-289. https://doi.org/10.1111/cob.12203

[17] Nam, S., Redeker, N. and Whittemore, R. (2015) Social Networks and Future Direction for Obesity Research: A Scoping Review. Nursing Outlook, 63, 299-317. https://doi.org/10.1016/j.outlook.2014.11.001

[18] Lyu, N., Azar, K.M.J., Rosas, L.G., Wulfovich, S., Xiao, L. and Ma, J. (2017) Behavioral Lifestyle Interventions for Moderate and Severe Obesity: A Systematic Review. Preventive Medicine, 100, 180-193. https://doi.org/10.1016/j.ypmed.2017.04.022

[19] Powell, K., Wilcox, J., Clonan, A., Bissell, P., Preston, L., Peacock, M., et al. (2015) The Role of Social Networks in the Development of Overweight and Obesity among Adults: A Scoping Review. BMC Public Health, 15, Article No. 996. https://doi.org/10.1186/s12889-015-2314-0

[20] Zhang, S., De La Haye, K., Ji, M. and An, R. (2018) Applications of Social Network Analysis to Obesity: A Systematic Review. Obesity Reviews, 19, 976-988. https://doi.org/10.1111/obr.12684

[21] Gesell, S.B., De La Haye, K., Sommer, E.C., Saldana, S.J., Barkin, S.L. and Ip, E.H. (2020) Identifying Social Network Conditions that Facilitate Sedentary Behavior Change: The Benefit of Being a "Bridge" in a Group-Based Intervention. International Journal of Environmental Research and Public Health, 17, Article No.4179. https://doi.org/10.3390/ijerph17124197

[22] Christakis, N.A. and Fowler, J.H. (2007) The Spread of Obesity in a Large Social Network Over 32 Years. New England Journal of Medicine, 357, 370-379.

https://doi.org/10.1056/NEJMsa066082

[23] Bahr, D.B., Browning, R.C., Wyatt, H.R. and Hill, J.O. (2009) Exploiting Social Networks to Mitigate the Obesity Epidemic. Obesity, 17, 723-728. https://doi.org/10.1038/oby.2008.615

[24] Pagkas-Bather, J., Young, L.E., Chen, Y.-T. and Schneider, J.A. (2020) Social Network Interventions for HIV Transmission Elimination. Current HIVIAIDS Reports, 17, 450-457. https://doi.org/10.1007/s11904-020-00524-Z 
[25] Hosseini, Z., Veenstra, G., Khan, N.A. and Conklin, A.I. (2020) Associations between Social Connections, Their Interactions, and Obesity Differ by Gender: A PopulationBased, Cross-Sectional Analysis of the Canadian Longitudinal Study on Aging. PLoS ONE, 15, Article No. e0235977. https://doi.org/10.1371/journal.pone.0235977

[26] Campbell, A.D. and Baker, E.H. (2019) Do Income Inequalities in Higher Weight Status Depend on Social Integration? Social Science Research, 83, Article ID: 102301. https://doi.org/10.1016/j.ssresearch.2019.04.014

[27] McLaren, L. (2007) Socioeconomic Status and Obesity. Epidemiologic Reviews, 29, 29-48. https://doi.org/10.1093/epirev/mxm001

[28] Zhang, Q. and Wang, Y. (2004) Socioeconomic Inequality of Obesity in the United States: Do Gender, Age, and Ethnicity Matter? Social Science \& Medicine, 58, 11711180. https://doi.org/10.1016/S0277-9536(03)00288-0

[29] Kim, K., Jung, S.J., Baek, J.M., Yim, H.W., Jeong, H., Kim, D.J., et al. (2020) Associations between Social Network Properties and Metabolic Syndrome and the Mediating Effect of Physical Activity: Findings from the Cardiovascular and Metabolic Diseases Etiology Research Center (CMERC) Cohort. BMJ Open Diabetes Research and Care, 8, Article ID: e001272. https://doi.org/10.1136/bmjdrc-2020-001272

[30] Florez, K.R., Richardson, A.S., Ghosh-Dastidar, M., Troxel, W., De Santis, A., Colabianchi, N., et al. (2018) The Power of Social Networks and Social Support in Promotion of Physical Activity and Body Mass Index among African American Adults. SSMPopulation Health, 4, 327-333. https://doi.org/10.1016/j.ssmph.2018.03.004

[31] Wieland, M.L., Njeru, J.W., Okamoto, J.M., Novotny, P.J., Breen-Lyles, M.K., Goodson, M., et al. (2020) Association of Social Network Factors with Weight Status and Weight Loss Intentions among Hispanic Adults. Journal of Behavioral Medicine, 43, 155-165. https://doi.org/10.1007/s10865-019-00131-3

[32] Barnett, E. and Casper, M. (2001) A Definition of "social Environment". American Journal of Public Health, 91, Article No. 465.

https://doi.org/10.2105/AJPH.91.3.465a

[33] Hoenink, J.C., Lakerveld, J., Rutter, H., Compernolle, S., De Bourdeaudhuij, I., Bardos, H., et al. (2019) The Moderating Role of Social Neighbourhood Factors in the Association between Features of the Physical Neighbourhood Environment and Weight Status. Obesity Facts, 12, 14-24. https://doi.org/10.1159/000496118

[34] Van Kim, N.A., Eisenberg, M.E., Erickson, D.J., Lust, K. and Laska, M.N. (2020) College Climate and Sexual Orientation Differences in Weight Status. Prevention Science, 21, 422-433. https://doi.org/10.1007/s11121-019-01061-x

[35] Lee, H. (2011) Inequality as an Explanation for Obesity in the United States. Sociology Compass, 5, 215-232. https://doi.org/10.1111/j.1751-9020.2010.00355.x

[36] Gudzune, K.A., Peyton, J., Pollack, C.E., Young, J.H., Levine, D.M., Latkin, C.A., et al. (2019) Overweight/obesity among Social Network Members Has an Inverse Relationship with Baltimore Public Housing Residents' BMI. Preventive Medicine Reports, 14, Article ID: 100809. https://doi.org/10.1016/j.pmedr.2019.01.013

[37] Datar, A. and Nicosia, N. (2018) Assessing Social Contagion in Body Mass Index, Overweight, and Obesity Using a Natural Experiment. JAMA Pediatrics, 172, 239-246. https://doi.org/10.1001/jamapediatrics.2017.4882

[38] Lee, B.Y., Bartsch, S.M., Mui, Y., Haidari, L.A., Spiker, M.L. and Gittelsohn, J. (2017) A Systems Approach to Obesity. Nutrition Reviews, 75, 94-106. https://doi.org/10.1093/nutrit/nuw049

[39] Harrison, J.D., Jones, J.M., Small, D.S., Rareshide, C.A.L., Szwartz, G., Steier, D., et al. (2019) Social Incentives to Encourage Physical Activity and Understand Predic- 
tors (STEP UP): Design and Rationale of a Randomized Trial among Overweight and Obese Adults Across the United States. Contemporary Clinical Trials, 80, 55-60. https://doi.org/10.1016/j.cct.2019.04.001

[40] Cockerham, W.C. (2005) Health Lifestyle Theory and the Convergence of Agency and Structure. Journal of Health and Social Behavior, 46, 51-67. https://doi.org/10.1177/002214650504600105

[41] Tomaka, J., Thompson, S. and Palacios, R. (2006) The Relation of Social Isolation, Loneliness, and Social Support to Disease Outcomes among the Elderly. Journal of Aging and Health, 18, 359-384. https://doi.org/10.1177/0898264305280993

[42] Pollack, C.E., Green, H.D.J., Kennedy, D.P., Griffin, B.A., Kennedy-Hendricks, A., Burkhauser, S., et al. (2014) The Impact of Public Housing on Social Networks: A Natural Experiment. American Journal of Public Health, 104, 1642-1649. https://doi.org/10.2105/AJPH.2014.301949

[43] Marcoux, B.C., Trenkner, L.L. and Rosenstock, I.M. (1990) Social Networks and Social Support in Weight Loss. Patient Education and Counseling, 15, 229-238. https://doi.org/10.1016/0738-3991(90)90098-6

[44] Pachucki, M.A., Jacques, P.F. and Christakis, N.A. (2011) Social Network Concordance in Food Choice among Spouses, Friends, and Siblings. American Journal of Public Health, 101, 2170-2177. https://doi.org/10.2105/AJPH.2011.300282

[45] Hystad, P. and Carpiano, R.M. (2012) Sense of Community-Belonging and Health-Behaviour Change in Canada. Journal of Epidemiology and Community Health, 66, 277-283. https://doi.org/10.1136/jech.2009.103556

[46] Yang, Y.C., Boen, C., Gerken, K., Li, T., Schorpp, K. and Harris, K.M. (2016) Social Relationships and Physiological Determinants of Longevity across the Human Life Span. Proceedings of the National Academy of Sciences of the United States of America, 113, 578-583. https://doi.org/10.1073/pnas.1511085112

[47] Huizar, M.I., Arena, R. and Laddu, D.R. (2021) The Global Food Syndemic: The Impact of Food Insecurity, Malnutrition and Obesity on the Healthspan Amid the COVID19 Pandemic. Progress in Cardiovascular Diseases, 64, 105-107. https://doi.org/10.1016/j.pcad.2020.07.002

[48] Clemmensen, C., Petersen, M.B. and Sørensen, T.I.A. (2020) Will the COVID-19 Pandemic Worsen the Obesity Epidemic? Nature Reviews Endocrinology, 16, 469-470. https://doi.org/10.1038/s41574-020-0387-Z

[49] Khan, M.A.B. and Moverley Smith, J.E. (2020) "Covibesity", a New Pandemic. Obesity Medicine, 19, Article ID: 100282. https://doi.org/10.1016/j.obmed.2020.100282

[50] Conley, D. and Glauber, R. (2006) Gender, Body Mass, and Socioeconomic Status: New Evidence from the PSID. In: Bolin, K. and Cawley, J., Eds., The Economics of Obesity, Vol. 17, Emerald Group Publishing Limited, Bingley, 253-275. https://doi.org/10.1016/S0731-2199(06)17010-7

[51] Kawachi, I., Adler, N.E. and Dow, W.H. (2010) Money, Schooling, and Health: Mechanisms and Causal Evidence. Annals of the New York Academy of Sciences, 1186, 56-68. https://doi.org/10.1111/j.1749-6632.2009.05340.x

[52] Taylor, S.E., Sherman, D.K., Kim, H.S., Jarcho, J., Takagi, K. and Dunagan, M.S. (2004) Culture and Social Support: Who Seeks It and Why? Journal of Personality and Social Psychology, 87, 354-362. https://doi.org/10.1037/0022-3514.87.3.354

[53] Kim, H. and Markus, H.R. (1999) Deviance or Uniqueness, Harmony or Conformity? A Cultural Analysis. Journal of Personality and Social Psychology, 77, 785-800. https://doi.org/10.1037/0022-3514.77.4.785

[54] Kim, H.S., Sherman, D.K., Ko, D. and Taylor, S.E. (2006) Pursuit of Comfort and 
Pursuit of Harmony: Culture, Relationships, and Social Support Seeking. Personality and Social Psychology Bulletin, 32, 1595-1607. https://doi.org/10.1177/0146167206291991

[55] Di Milia, L. and Mummery, K. (2009) The Association between Job Related Factors, Short Sleep and Obesity. Industrial Health, 47, 363-368.

https://doi.org/10.2486/indhealth.47.363

[56] Hoebel, J., Kuntz, B., Kroll, L.E., Schienkiewitz, A., Finger, J.D., Lange, C., et al. (2019) Socioeconomic Inequalities in the Rise of Adult Obesity: A Time-Trend Analysis of National Examination Data from Germany, 1990-2011. Obesity Facts, 12, 344-356. https://doi.org/10.1159/000499718

[57] Hoffmann, K., De Gelder, R., Hu, Y., Bopp, M., Vitrai, J., Lahelma, E., et al. (2017) Trends in Educational Inequalities in Obesity in 15 European Countries between 1990 and 2010. International Journal of Behavioral Nutrition and Physical Activity, 14, Article No. 63. https://doi.org/10.1186/s12966-017-0517-8

[58] Haglund, B.J.A. (1987) Geographical and Socioeconomic Distribution of Overweight and Morbidity in a Rural Swedish County. Scandinavian Journal of Social Medicine, 15, 19-29. https://doi.org/10.1177/140349488701500104

[59] Gutiérrez-Fisac, J.L., Guallar-Castillón, P., Díez-Gañán, L., García, E.L., Banegas, J.R.B. and Artalejo, F.R. (2002) Work-Related Physical Activity Is Not Associated with Body Mass Index and Obesity. Obesity Research, 10, 270-276. https://doi.org/10.1038/oby.2002.37

[60] Nickels, N., Kubicki, K. and Maestripieri, D. (2017) Sex Differences in the Effects of Psychosocial Stress on Cooperative and Prosocial Behavior: Evidence for 'Flight or Fight' in Males and 'Tend and Befriend' in Females. Adaptive Human Behavior and Physiology, 3, 171-183. https://doi.org/10.1007/s40750-017-0062-3

[61] Schulte, P.A., Wagner, G.R., Ostry, A., Blanciforti, L.A., Cutlip, R.G., Krajnak, K.M., et al. (2007) Work, Obesity, and Occupational Safety and Health. American Journal of Public Health, 97, 428-436. https://doi.org/10.2105/AJPH.2006.086900

[62] Wardle, J., Steptoe, A., Oliver, G. and Lipsey, Z. (2000) Stress, Dietary Restraint and Food Intake. Journal of Psychosomatic Research, 48, 195-202. https://doi.org/10.1016/S0022-3999(00)00076-3

[63] Hajek, A. and König, H.-H. (2018) The Association between Obesity and Social Exclusion in Middle-Aged and Older Adults: Findings from a Nationally Representative Study in Germany. BMC Geriatrics, 18, Article No. 258. https://doi.org/10.1186/s12877-018-0946-5

[64] Matos, A.D., Barbosa, F., Cunha, C., Voss, G. and Correia, F. (2021) Social Isolation, Physical Inactivity and Inadequate Diet among European Middle-Aged and Older Adults. BMC Public Health, 21, Article No. 924. https://doi.org/10.1186/s12889-021-10956-w

[65] Schrempft, S., Jackowska, M., Hamer, M. and Steptoe, A. (2019) Associations between Social Isolation, Loneliness, and Objective Physical Activity in Older Men and Women. BMC Public Health, 19, Article No. 74. https://doi.org/10.1186/s12889-019-6424-y

[66] Hämmig, O. (2019) Health Risks Associated with Social Isolation in General and in Young, Middle and Old Age. PLoS ONE, 14, Article ID: e0219663. https://doi.org/10.1371/journal.pone.0219663

[67] Zhang, J., Tong, L., Lamberson, P.J., Durazo-Arvizu, R.A., Luke, A., Shoham, D.A. (2015) Leveraging Social Influence to Address Overweight and Obesity Using AgentBased Models: The Role of Adolescent Social Networks. Social Science \& Medicine, 125, 203-213. https://doi.org/10.1016/j.socscimed.2014.05.049 
[68] Carson, T.L., Eddings, K.E., Krukowski, R.A., Love, S.J., Harvey-Berino, J.R. and West, D.S. (2013) Examining Social Influence on Participation and Outcomes among a Network of Behavioral Weight-Loss Intervention Enrollees. Journal of Obesity, 2013, Article ID: 480630. https://doi.org/10.1155/2013/480630

[69] Cohen, D.A., Finch, B.K., Bower, A. and Sastry, N. (2006) Collective Efficacy and Obesity: The Potential Influence of Social Factors on Health. Social Science \& Medicine, 62, 769-778. https://doi.org/10.1016/j.socscimed.2005.06.033

[70] McCormack, G.R., Friedenreich, C., McLaren, L., Potestio, M., Sandalack, B., Csizmadi, I. (2017) Interactions between Neighbourhood Urban Form and Socioeconomic Status and Their Associations with Anthropometric Measurements in Canadian Adults. Journal of Environmental and Public Health, 2017, Article ID: 5042614. https://doi.org/10.1155/2017/5042614

[71] Poortinga, W. (2006) Perceptions of the Environment, Physical Activity, and Obesity. Social Science \& Medicine, 63, 2835-284.

https://doi.org/10.1016/j.socscimed.2006.07.018

[72] McFerran, B., Dahl, D.W., Fitzsimons, G.J. and Morales, A.C. (2010) Might an Overweight Waitress Make You Eat More? How the Body Type of Others Is Sufficient to Alter Our Food Consumption. Journal of Consumer Psychology, 20, 146-151. https://doi.org/10.1016/j.jcps.2010.03.006

[73] Pearce, J., Day, P. and Witten, K. (2008) Neighbourhood Provision of Food and Alcohol Retailing and Social Deprivation in Urban New Zealand. Urban Policy and Research, 26, 213-227. https://doi.org/10.1080/08111140701697610

[74] Schneider, S. and Gruber, J. (2013) Neighbourhood Deprivation and Outlet Density for Tobacco, Alcohol and Fast Food: First Hints of Obesogenic and Addictive Environments in Germany. Public Health Nutrition, 16, 1168-1177. https://doi.org/10.1017/S1368980012003321

[75] Morland, K., Wing, S., Roux, A.D. and Poole, C. (2002) Neighborhood Characteristics Associated with the Location of Food Stores and Food Service Places. American Journal of Preventive Medicine, 22, 23-29. https://doi.org/10.1016/S0749-3797(01)00403-2

[76] Suehazlyn, Z., Daud, Z., Masni, M., Boon, A.T.T. and Wan, M.W.M.I. (2011) A Summary of the Malaysian Clinical Practice Guidelines on Management of Obesity 2004. Journal of the ASEAN Federation of Endocrine Societies, 2011, 101-104. https://doi.org/10.15605/jafes.026.2.03

[77] Luppino, F.S., De Wit, L.M., Bouvy, P.F., Stijnen, T., Cuijpers, P., Penninx, B.W.J.H., et al. (2010) Overweight, Obesity, and Depression: A Systematic Review and MetaAnalysis of Longitudinal Studies. Archives of General Psychiatry, 67, 220-229. https://doi.org/10.1001/archgenpsychiatry.2010.2

[78] Huet, L., Delgado, I., Aouizerate, B., Castanon, N. and Capuron, L. (2019) Chapter 16: Obesity and Depression: Shared Pathophysiology and Translational Implications. In: Quevedo, J., Carvalho, A.F. and Zarate, C.A., Eds., Neurobiology of Depression, Academic Press, Cambridge, 169-183. https://doi.org/10.1016/B978-0-12-813333-0.00016-0

[79] Boitard, C., Cavaroc, A., Sauvant, J., Aubert, A., Castanon, N., Layé, S., et al. (2014) Impairment of Hippocampal-Dependent Memory Induced By Juvenile High-Fat Diet Intake Is Associated with Enhanced Hippocampal Inflammation in Rats. Brain, Behavior, and Immunity, 40, 9-17. https://doi.org/10.1016/j.bbi.2014.03.005

[80] Björntorp, P. (2001) Do Stress Reactions Cause Abdominal Obesity and Comorbidities? Obesity Reviews, 2, 73-86. https://doi.org/10.1046/j.1467-789x.2001.00027.x 
[81] Milano, W., Ambrosio, P., Carizzone, F., De Biasio, V., Di Munzio, W., Foia, M.G., et al. (2020) Depression and Obesity: Analysis of Common Biomarkers. Diseases, 8, Article No. 23. https://doi.org/10.3390/diseases 8020023

[82] Wilbur, C.S., Zifferblatt, S.M., Pinsky, J.L. and Zifferblatt, S. (1981) Healthy Vending: A Cooperative Pilot Research Program to Stimulate Good Health in the Marketplace. Preventive Medicine, 10, 85-93. https://doi.org/10.1016/0091-7435(81)90009-8

[83] Moore, L.V., Roux, A.V.D., Nettleton, J.A. and Jacobs, D.R.J. (2008) Associations of the Local Food Environment with Diet Quality-A Comparison of Assessments Based on Surveys and Geographic Information Systems: The Multi-Ethnic Study of Atherosclerosis. American Journal of Epidemiology, 167, 917-924. https://doi.org/10.1093/aje/kwm394

[84] Zimmerman, F.J. and Shimoga, S.V. (2014) The Effects of Food Advertising and Cognitive Load on Food Choices. BMC Public Health, 14, Article No. 342. https://doi.org/10.1186/1471-2458-14-342

[85] Saffer, H. and Chaloupka, F. (2000) The Effect of Tobacco Advertising Bans on Tobacco Consumption. Journal of Health Economics, 19, 1117-1137. https://doi.org/10.1016/S0167-6296(00)00054-0

[86] Darmon, N. and Drewnowski, A. (2008) Does Social Class Predict Diet Quality? The American Journal of Clinical Nutrition, 87, 1107-1117. https://doi.org/10.1093/ajcn/87.5.1107

[87] Guo, X., Popkin, B.M., Mroz, T.A. and Zhai, F. (1999) Food Price Policy Can Favorably Alter Macronutrient Intake in China. The Journal of Nutrition, 129, 994-1001. https://doi.org/10.1093/jn/129.5.994

[88] Jeffery, R.W. (2001) Public Health Strategies for Obesity Treatment and Prevention. American Journal of Health Behavior, 25, 252-259. https://doi.org/10.5993/AJHB.25.3.12

[89] Sallis, J.F., Frank, L.D., Saelens, B.E. and Kraft, M.K. (2004) Active Transportation and Physical Activity: Opportunities for Collaboration on Transportation and Public Health Research. Transportation Research Part A: Policy and Practice, 38, 249-268. https://doi.org/10.1016/j.tra.2003.11.003

[90] Sallis, J.F., Hovell, M.F., Hofstetter, C.R., Elder, J.P., Hackley, M., Caspersen, C.J., et al. (1990) Distance between Homes and Exercise Facilities Related to Frequency of Exercise among San Diego Residents. Public Health Reports, 105, 179-185.

[91] Brownson, R.C., Housemann, R.A., Brown, D.R., Jackson-Thompson, J., King, A.C., Malone, B.R., et al. (2000) Promoting Physical Activity in Rural Communities: Walking Trail Access, Use, and Effects. American Journal of Preventive Medicine, 18, 235-241. https://doi.org/10.1016/S0749-3797(99)00165-8

[92] Wagner, A., Simon, C., Ducimetière, P., Montaye, M., Bongard, V., Yarnell, J., et al. (2001) Leisure-Time Physical Activity and Regular Walking or Cycling to Work Are Associated with Adiposity and 5 Y Weight Gain in Middle-Aged Men: The PRIME Study. International Journal of Obesity, 25, 940-948.

https://doi.org/10.1038/sj.ijo.0801635 